\title{
A HIGH INTENSITY BEAM ABSORBER COREBOX FOR THE FERMILAB MAIN INJECTOR ABORT SYSTEM
}

\author{
M. Reichanadter, C.M. Bhat, C. Crawford, P.S. Martin \\ Fermi National Accelerator Laboratory* \\ P.O. Box 500, Batavia, Illinois 60510
}

\section{INTRODUCTION}

The beam abort system proposed [1] for the Fermilab Main Injector will extract a proton beam from the accelerator in a single turn $(\sim 10 \mu \mathrm{sec})$ and direct it to an external beam absorber, of which the corebox is the central component. The primary design constraint of the corebox is to absorb an incident proton beam in a safe, efficient manner and transfer its energy to the primary cooling loop of the Abort Core cooling system. Additionally, it is clearly necessary, due to the induced radioactivity in and around the beam absorber, that the corebox be maintenance-free and have a lifetime equal to that of the Main Injector Accelerator, 20 years.

To achieve the above constraints, the corebox design must satisfy three primary aspects; absorb incident and secondary particles such that radiation levels are maintained below PSAR limits [2], efficiently transfer bulk heat to the cooling system, and dissipate mechanical wave propagation resulting from the sudden deposition of beam energy.

\section{BEAM ABSORBER DESIGN REQUIREMENTS}

The upper bound parameters of a single aborted beam pulse are listed below[2];

\begin{tabular}{|l|c|}
\hline beam energy & $150 \mathrm{GeV}$ \\
\hline beam type & proton \\
\hline total kinetic energy & $2.4 \mathrm{MJ}$ \\
\hline pulse duration & $10 \mu \mathrm{sec}$ \\
pulse rate & $0.53 \mathrm{~Hz}$ \\
\hline \#particles/spill & $1.00 \mathrm{E}+14$ \\
\hline $\begin{array}{l}\text { transverse beam size } \\
\left(\sigma_{\mathrm{x}}=\sigma_{\mathrm{y}}\right) \text { Gaussian beam } \\
\text { distribution }\end{array}$ \\
\hline
\end{tabular}

With regard to repeated beam aborts and the yearly average beam we have the following specifications[2];

\begin{tabular}{|l|c|}
\hline $\begin{array}{l}\text { short term continuous } \\
\text { operation }\end{array}$ & $\begin{array}{c}1 \mathrm{E}+14 \mathrm{ppp} @ 150 \mathrm{GeV} \\
\text { with a } 1.9 \text { sec cycle time } \\
\text { for 1 hour duration }\end{array}$ \\
average power input & $1.28 \mathrm{MW}$ \\
\hline & $2.124 \mathrm{E}+19 \mathrm{p} / \mathrm{yr} @$ \\
yearly proton flux & $150 \mathrm{GeV}$ \\
\hline
\end{tabular}

\footnotetext{
* Operated by Universities Research Association, Inc., under Contract No. DE-AC02-76CH03000 with the U.S. Department of Energy.
}

\section{ENERGY DEPOSITION ANALYSIS}

Energy deposition due to high energy particle beam interaction within the abort system per proton pulse has been calculated using the Monte Carlo computer code MARS13 which simulates the three dimensional hadron and electromagnetic cascades. The analysis assumes radial symmetry and the energy deposition is calculated on a per grid zone basis. The radial zone size varies from $0.06 \mathrm{~cm}$ near the beam axis to $2.54 \mathrm{~cm}$ at the outer perimeter. Along the azimuthal axis, $\Delta \mathrm{z}$ is fixed at $12.20 \mathrm{~cm}$.

For a single beam spill, the maximum energy deposition for the corebox materials (carbon, aluminum) and the steel shielding (downstream of the corebox) is shown in the figure below.

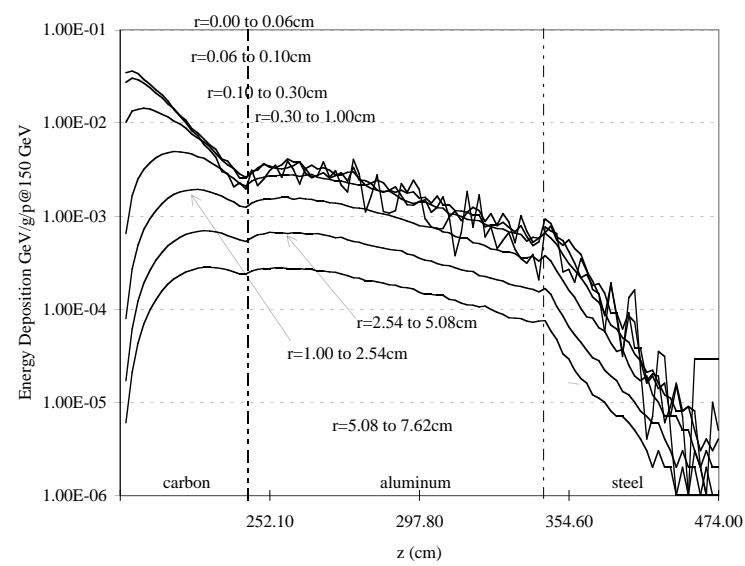

Figure1. Energy deposition in MI Abort Corebox (Mars13).

A summary of the maximum energy deposition values and related temperature increase is shown below.

\begin{tabular}{|l|c|c|c|}
\hline & Carbon & Aluminum & Steel \\
\hline energy $(\mathrm{GeV} / \mathrm{g} / \mathrm{p})$ & $3.60 \mathrm{E}-02$ & $4.11 \mathrm{E}-03$ & $9.32 \mathrm{E}-04$ \\
\hline energy $(\mathrm{J} / \mathrm{g})$ & 576.72 & 65.84 & 14.93 \\
\hline $\mathrm{T}($ degrees C) & 469.00 & 72.00 & 33.00 \\
\hline
\end{tabular}

\section{COREBOX DESIGN}

The Abort Corebox, shown in Figure 2, consists of eight, 12-inch long, 6-inch diameter cylinders of isostatically-molded, fine grain, high purity carbon, which are held in an 11-foot long aluminum water jacket with a light shrinkfit (0.002"). The shrinkfit is necessary to insure good thermal contact between the carbon cylinders and the aluminum water jacket. This design length, 96 
inches of carbon, followed by 36 inches of aluminum is sufficient to absorb approximately $800 \mathrm{~kW}$ (average power) of the beam's total energy, with the remainder deposited in the steel shielding downstream of the corebox. The corebox housing is made of aluminum 6061-T6, a weldable, machinable, moderate strength alloy having good corrosion resistance.

A 0.010 " thick titanium window seals and separates the carbon cylinders in an argon environment, to prevent oxidation of the carbon at elevated temperatures. Energy deposition calculations predict that the titanium window will reach a peak temperature of $386.68 \mathrm{~K}$ in about 45 pulses at $1 \mathrm{E}+14 \mathrm{ppp}$. The temperature of the carbon cylinders and the aluminum corebox are monitored using high temperature thermocouples (Type J, 0.125 " dia.).

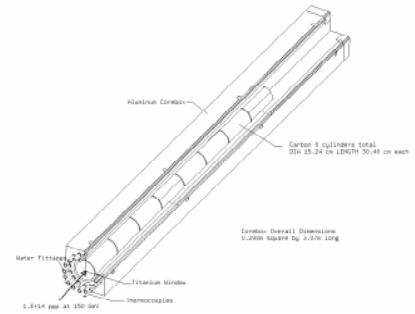

Figure 2. Cutaway isometric of the Abort Corebox

The primary cooling system for the Abort Corebox has a flow rate of $160 \mathrm{gpm}(\Delta \mathrm{p}=3.8 \mathrm{psi})$ with eight parallel paths through the aluminum section of the corebox. The aluminum surface temperature is approximately $68 \mathrm{C}$, with the $\Delta \mathrm{T}$ of the water at $16 \mathrm{C}$, and a film coefficient of $10500 \mathrm{~W} / \mathrm{m} 2-\mathrm{K}$. Prolonged exposure to beam environments, leading to the production of tritium, require an all-welded system design.

\section{THERMAL CONSIDERATIONS}

Using the energy deposition values per Main Injector proton pulse as an input, the temperature increase associated with each pulse can be carried out over time, until a quasi-steady state is reached. At this point average power into the abort equals the average power dissipated, and the storage term drops to zero. Separate analysis for the carbon, aluminum and steel were evaluated using the finite element code ANSYS $^{\circledR}$, with the following assumptions and boundary conditions;

- $\quad$ unsteady, non-linear energy deposition $(\mathrm{C}, \mathrm{Al})$

- energy deposition is in discrete zones $(\mathrm{r}, \mathrm{z})$

- $\quad$ transient, 2-D conduction( $\mathrm{r}, \mathrm{z})$

- $\rho=$ constant, $k$ and $c_{p}=f(T) \operatorname{Ref}[3]$

- constant temperature boundary at $\mathrm{r}=7.62 \mathrm{~cm}(\mathrm{C}, \mathrm{Al})$

- $\quad$ adiabatic boundary on cylinder ends, $\partial \mathrm{T} / \partial \mathrm{z}=0(\mathrm{C}, \mathrm{Al})$

- natural convection and radiation heat transfer at the Fe boundary $\mathrm{r}=22.86 \mathrm{~cm}, 1=213.36 \mathrm{~cm}$

- $\quad$ steady, non-linear energy deposition (Fe only)

- $\quad$ shape factor=1.0, emmissivity=1.0 (Fe only)

Single pulse results of the finite element analysis for the carbon and aluminum predict the highest $\Delta \mathrm{T}$ values of
456.1 in the carbon and 66.8 degrees $C$ for the aluminum. Average deviation with the MARS13 analysis is less than $5 \%$. Carrying the analysis forward in time, the carbon and aluminum sections reach the quasi-steady state point in about 80 and 25 pulses, respectively, as shown in Figure 3.

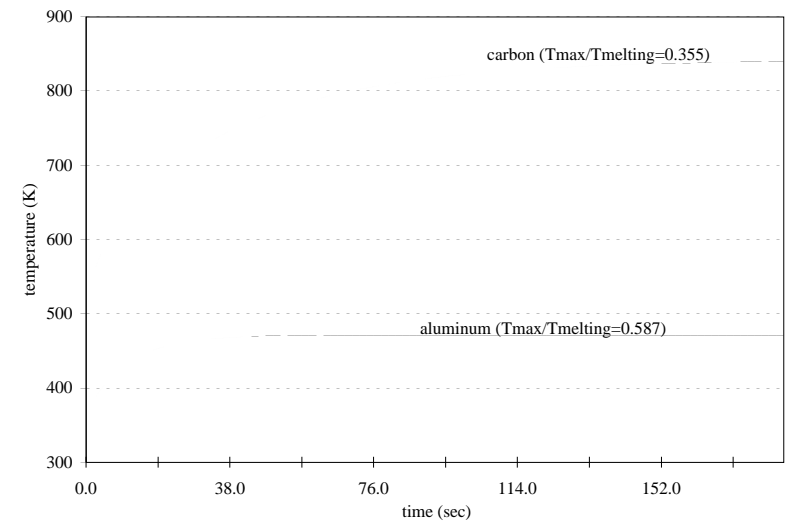

Figure 3. Maximum nodal temperature versus time for the carbon and aluminum sections.

Downstream of the corebox consists of a series of steel shielding slabs 84 "high x 84 "wide x 121 " in length. The total energy $(57 \mathrm{GeV} / \mathrm{p} @ 150 \mathrm{Gev})$ is deposited directly in a single central slab 18"high x 51" wide x 66"in length.

A steady-state solution for the steel was investigated using the first pulse radial and azimuthal energy deposition values averaged over time. Heat transfer from the steel shielding was conservatively modeled as a single right circular cylinder $(\mathrm{r}=22.86 \mathrm{~cm}, \mathrm{l}=213.36 \mathrm{~cm})$, using natural convection and radiation at the boundary as the transport mechanisms. The results of this analysis predict the maximum temperature in the slab of $1437 \mathrm{~K}$ (Tmax/Tmelting $=0.807$ ) while transferring $480 \mathrm{~kW}$ to the surrounding atmosphere.

\section{STRESS WAVE CONSIDERATIONS}

The deposition of a large amount of beam energy over a few micro-second duration results in rapid material expansion due to high temperatures causing dynamic stresses that propagate through the material at the velocity of sound. Dynamic stress waves can be potentially destructive, if either the incident wave imparted by the beam, or the reflected wave returning from the free surface exceeds the fatigue strength of the material. For a perfectly constrained body under thermoelastic pressure increase due to energy deposition, we have,

$$
p=\frac{E}{1-2 v} \alpha(\Delta \mathrm{T})
$$

Where $\mathrm{E}=$ the elastic modulus, $v=$ Poisson's ratio, and $\alpha=$ the linear expansion coefficient. Applying this to the highest energy deposition zones in the carbon and aluminum gives values of $25 \mathrm{MPa}$ and $337 \mathrm{MPa}$, respectively. From this conservative estimate we can determine both materials are well below their yield 
strength, and assume that only elastic waves are present. The details of the stress waves imparted in the MI Abort carbon and aluminum were investigated using the ANSYS program, using the following assumptions and boundary conditions;

- $\quad$ one-dimensional transverse elastic waves are present

- material is initially at rest, and stress free

- axisymmetric model, at $\mathrm{r}=0.0 \mathrm{~cm}$, deflection $=0.0 \mathrm{~cm}$

- constrained boundary at $\mathrm{r}=7.62 \mathrm{~cm}$, deflection $=0.0 \mathrm{~cm}$ (carbon only)

- $\quad$ ignore water passages in cross-section (aluminum only)

- linear material properties

- $\quad$ reflection coefficient $=100 \%$

For the carbon cylinders, the outer radial boundary is constrained by the shrink fit, resulting in the incident compressive wave being fully reflected as a compressive wave. This returning wave is focused radially on the region surrounding the centerline of the carbon, and returns at the beam axis centerline in approximately $50 \mu \mathrm{sec}$. Element size chosen for the carbon analysis is $0.5 \mathrm{~mm}$ (152 elements total), with a wave speed of $\mathrm{c}=(\mathrm{E} / \rho)^{0.5}(\approx 2600 \mathrm{~m} / \mathrm{s})$. The time step used to resolve the dynamic wave is $0.065 \mu \mathrm{sec}$, roughly $1 / 3$ of the ratio $\Delta \mathrm{r} / \mathrm{c}$ to ensure stability[4]. Total time for the analysis is $80 \mu \mathrm{sec}$, which is sufficient for the incident wave to be reflected off the outer boundary and return to the central beam axis. The analysis indicates that the incident beam imparts a compressive radial stress of $9.0 \mathrm{MPa}(-1300 \mathrm{psi})$, with the returning reflected wave increasing the compressive stress to $10.0 \mathrm{MPa}$ (-1450psi), both significantly less than the carbon compressive yield strength of $90 \mathrm{MPa}$, as displayed in Figure 4. Circumferential stresses were found to be equal or lower than the radial stresses.

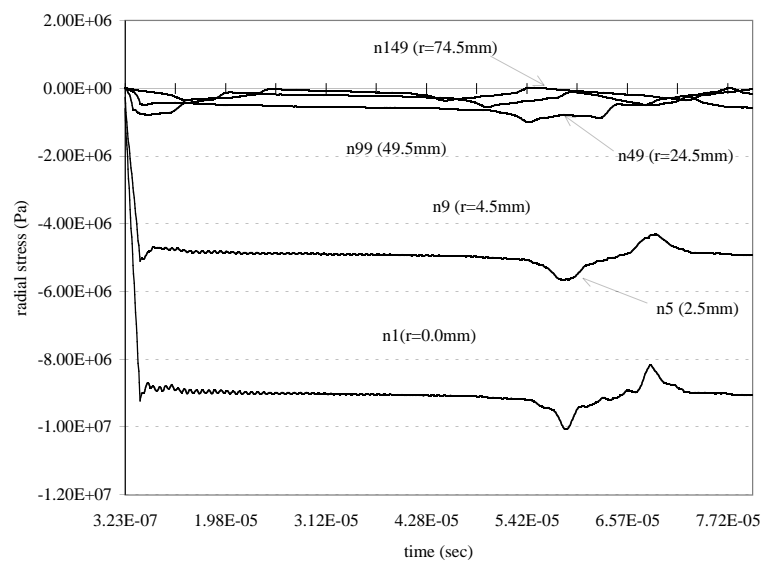

Figure 4. Radial pressure wave resolved for selected nodes in the carbon section of the MI Abort Corebox.

The aluminum section of the corebox was modeled as a square prism with a center to edge distance of $15.24 \mathrm{~cm}$. Higher stress peaks are expected in the aluminum section due to a high expansion coefficient. Additionally, the outer edge of the aluminum is a free surface, resulting in a reflected tensile wave, rather than a compressive wave, as in the carbon. Tensile waves can lead to density decrease in the material, and fracture if the tensile strength is exceeded.

Using $\Delta \mathrm{r}=0.5 \mathrm{~mm}$ with 2400 time steps over $75 \mu \mathrm{sec}$ time span $\left(c=(E / \rho)^{0.5} \approx 5100 \mathrm{~m} / \mathrm{s}\right.$ for aluminum $)$, the results of the analysis reveal a radial compressive stress of $49.0 \mathrm{MPa}$ (7100psi) from the incident beam. The reflected wave, focused along the centerline of the aluminum, is found to be $67.0 \mathrm{MPa}$ (9700psi). This analysis is considered conservative since there was no consideration of the water channels that form a radial pattern through the aluminum corebox. This array of holes will help to disperse the outgoing compressive wave, and diffuse the reflected ingoing tensile wave. The 9700 psi tensile peak, $42 \%$ of the aluminum's fatigue strength is considered acceptable. Figures 5 below illustrates the principal stress imparted by the incident and reflected waves.

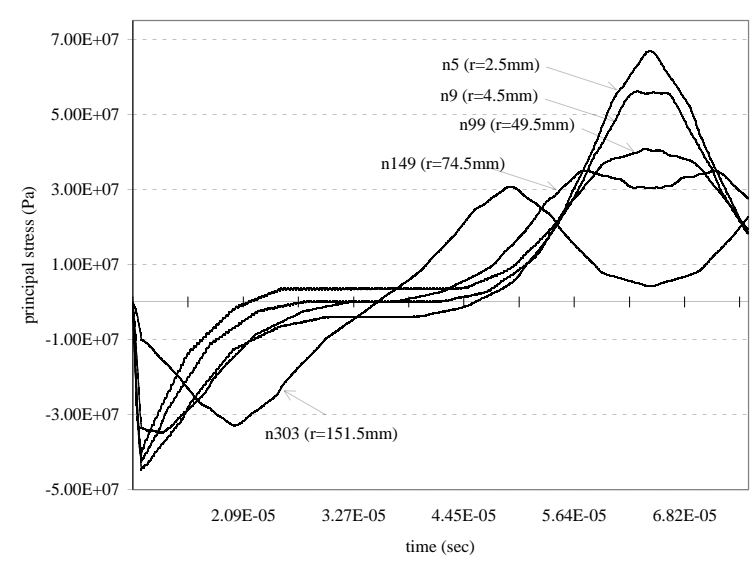

Figure 5. Principal stress wave resolved for selected nodes in the aluminum section of the MI Abort Corebox.

\section{ACKNOWLEDGMENTS}

We thank K. Anderson, Z. Tang, and the people at ANSYS for helpful discussions on the corebox analysis, J. Bielicki and S. Wesseln for assistance on the presentation of this paper, R. Rauchmiller and R. Dunklin for the assembly of the corebox, and D. Snee and the Fermilab machine shops for their advice in fabrication and assembly.

\section{REFERENCES}

[1] 'Fermilab Main Injector Technical Design Book', August 1994.

[2] Bhat, C.M., MI-0086, 'A Design Study of the MI-40 Beam Abort Dump', 1993.

[3] F.P. Incropera and D.P. DeWitt, 'Fundamentals of Heat and Mass Transfer', New York: John Wiley \& Sons, 1985.

[4] Z. Tang, "Elastic Waves in a Cylinder under Thermal Shock Loading', Internal Fermilab Memo, 1990. 